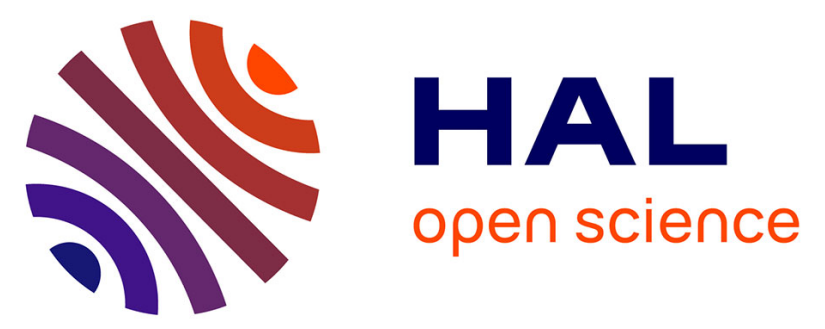

\title{
Parental history of type 2 diabetes, TCF7L2 variant and lower insulin secretion are associated with incident hypertension. Data from the DESIR and RISC cohorts.
}

Fabrice Bonnet, Ronan Roussel, Andrea Natali, Stéphane Cauchi, John Petrie, Martine Laville, Loïc Yengo, Philippe Froguel, Céline Lange, Olivier Lantieri, et al.

\section{To cite this version:}

Fabrice Bonnet, Ronan Roussel, Andrea Natali, Stéphane Cauchi, John Petrie, et al.. Parental history of type 2 diabetes, TCF7L2 variant and lower insulin secretion are associated with incident hypertension. Data from the DESIR and RISC cohorts.. Diabetologia, 2013, 56 (11), pp.2414-2423. 10.1007/s00125-013-3021-y . inserm-00871506

\section{HAL Id: inserm-00871506 https://www.hal.inserm.fr/inserm-00871506}

Submitted on 12 Aug 2014

HAL is a multi-disciplinary open access archive for the deposit and dissemination of scientific research documents, whether they are published or not. The documents may come from teaching and research institutions in France or abroad, or from public or private research centers.
L'archive ouverte pluridisciplinaire HAL, est destinée au dépôt et à la diffusion de documents scientifiques de niveau recherche, publiés ou non, émanant des établissements d'enseignement et de recherche français ou étrangers, des laboratoires publics ou privés. 


\section{Parental history of type 2 diabetes, TCF7L2 variant and lower insulin secretion are associated with incident hypertension. Data from the D.E.S.I.R. and RISC cohorts}

Fabrice Bonnet ${ }^{1}$; Ronan Roussel ${ }^{2}$; Andrea Natali ${ }^{3}$ Stéphane Cauchi $^{4}$; John Petrie ${ }^{5}$ Martine $^{4}$ Laville $^{6}$; Loïc Yengo ${ }^{4}$; Philippe Froguel ${ }^{4,7}$; Céline Lange ${ }^{8}$; Olivier Lantieri ${ }^{9}$; Michel Marre $^{2,10}$ Beverley Balkau $^{8}$ ELE Ferrannini ${ }^{3}$ for the D.E.S.I.R. and RISC Study Groups

${ }^{1}$ Service Endocrinologie-Diabétologie, CHU Rennes, Université Rennes 1, Inserm UMR991, Rennes, France : email: fabrice.bonnet@ chu-rennes.fr.

${ }^{2}$ Université Paris Diderot; AP-HP, Hôpital Bichat, Diabetology Endocrinology Nutrition, Paris, France ; INSERM U872, Paris, France

${ }^{3}$ Department of Internal Medicine, University of Pisa, Italy

${ }^{4}$ CNRS-UMR-8090, Institute of Biology, Lille 2 University, Pasteur Institute, Lille, France

${ }^{5}$ BHF Glasgow Cardiovascular Research Centre, University of Glasgow, UK

${ }^{6}$ Centre de Recherche en Nutrition Humaine, CRNH Rhône-Alpes,INSERM U 870-INRA1235, Lyon, France

${ }^{7}$ Genomic Medicine, Hammersmith Hospital, Imperial College London, London, U.K

${ }^{8}$ Inserm, Centre for research in Epidemiology and Population Health (CESP), U1018, Epidemiology of diabetes, obesity and chronic renal disease over the lifecourse, Villejuif, France, Univ Paris-Sud, UMRS 1018, Villejuif, France

${ }^{9}$ IRSA, La Riche, France

${ }^{10}$ INSERM, U695, Paris, France

Running title: Insulin secretion and incident hypertension

Text: 3942 words

4 tables and 1 figure

Abstract: 250 words

Corresponding author:

Prof Fabrice Bonnet,

Service Endocrinologie-Diabétologie,

CHU Rennes, Université Rennes 1, Inserm UMR 991, Rennes, France

Email: fabrice.bonnet@ chu-rennes.fr. Phone: +332992671 42; Fax: +332992671 49 


\begin{abstract}
Aims/hypothesis. The relation between insulin secretion and the incidence of hypertension has not been well characterized. We hypothesised that both a parental history of diabetes and the TCF7L2 polymorphism, which increases susceptibility todiabetesbecause of impaired beta cell function, are associated with incident hypertension. We assessed in a separate cohort whether low insulin secretion is related to incident hypertension.
\end{abstract}

Methods Nine-year incident hypertensionwas studied in 2391 normotensive participants from the D.E.S.I.R. cohort.The relation between insulin secretion and 3-year incident hypertension was investigated in 1047 non-diabetic, normotensive individuals from the RISC cohort. Insulin secretion during an OGTT was expressed in relation to the degree of insulin resistance, as assessed by a hyperinsulinemic-euglycemic clamp.

Results In the D.E.S.I.R. cohort, a parental history of diabetes and the TCF7L2 at-risk variant were both associated with hypertension incidence at year-9, independently of waist, blood pressure, fasting glucose, insulin levels and the HOMA-IR at inclusion ( $p=0.02$ for parental history, $p=0.006$ for TCF7L2). In the RISC cohort, a lower insulin secretion rate during the OGTT at baseline was associated with both higher blood pressure and a greater risk of hypertension at year-3. This inverse correlationbetween the insulin secretion rate and incident hypertension persisted after controlling for baseline insulin resistance, glycaemia and blood pressureat baseline $(p=0.007)$.

Conclusions/interpretationParental history of diabetes, the TCF7L2polymorphism and a reduced insulin secretion rate were consistently associated with incident hypertension. A low insulin secretion rate may be a new risk factor for incident hypertension, beyond insulin resistance.

Keywords: hypertension, insulin secretion,parental history of diabetes, TCF7L2, type 2 diabetes 
Abbreviations:

D.E.S.I.R.: Data from an Epidemiological Study on the Insulin Resistance syndrome HOMA2-IR: HOMA of insulin resistance

HOMA2\%B: HOMA of beta cell function

OGTT: Oral glucose tolerance test

RISC: Relationship between Insulin Sensitivity and Cardiovascular disease 


\section{Introduction}

Hypertension and type 2 diabetes are strongly interrelated and may share common environmental risk factors such as sedentary behaviours, visceral adiposity and insulin resistance[1]. Elevated blood pressure confers an increased risk for incident type 2 diabetes in the general population [2] and hypertension treatments may also modulate the risk of diabetes [3]. Fasting blood glucose, hyperinsulinemia and $\mathrm{HbAlc}$ have been associated with the development of hypertension in nondiabetic individuals [4-8]. However, the pathophysiology underlying the association between elevated glycemia and incident hypertension has not been well characterized. In particular, the impact on incident hypertension of a parental history of diabetes or genetic predisposition to type 2 diabetes, which is mainly associated with beta cell dysfunction [9], is not known. Furthermore, although the epidemiological link between insulin resistance and hypertension is recognized, the relation between insulin secretion and the incidence of hypertension and elevated blood pressure has not been investigated in the general population.

The aim of our study was to assess in the prospective D.E.S.I.R. cohort, the impact of a genetic predisposition to type 2 diabetes, on the development of hypertension. We analyzedthe impact of the TCF7L2 polymorphismon incident hypertension, because this polymorphism has the largest effect on susceptibility to diabetes among the predisposing genes discovered to date [10]. As we observed an association with the TCF7L2 at-risk allele, we tested whether defects in insulin secretion predispose to 3-year incident hypertension, in 1047 non-hypertensive, non-diabetic participants from the RISC cohort, all of whom had an accurate evaluation at baseline of both insulin sensitivity by the hyperinsulinaemic-euglycaemic clamp and insulin secretion from an extended OGTT [11]. 


\section{Research Design and Methods}

\section{The D.E.S.I.R. cohort}

We studied men and women aged 30-65 years, who participated in the 9-year follow-up study, Data from an Epidemiological Study on the Insulin Resistance Syndrome (D.E.S.I.R.). Participants were recruited from volunteers offered periodic health examinations free of charge by the French Social Security, in 10 health examinations centres in western France[12, 13]. All signed an informed consent and the protocol was approved by an ethics committee.Cases of hypertension were defined by treatment for hypertension or resting blood pressure $\geq 140$ (systolic) or $\geq 90$ (diastolic) $\mathrm{mmHg}$ at one of the four three-yearly examinations. After exclusion of individuals with hypertension at baseline, we studied 2391 participants with genotype data for TCF7L2 (745 had incident hypertension during the follow-up).

\section{Clinical assessment}

Two measures of blood pressure, using a mercury sphygmomanometer, were taken in a supine position after 5 minutes rest; mean values were used. Weight and height were measured in lightly clad participants, and body mass index (BMI) calculated. The examining physician noted the parental history of diabetes in a clinical questionnaire; treatment for diabetes and hypertension were recorded at each of the three yearly examinations.Smoking habits and alcohol intake were recorded in an auto-questionnaire.

\section{Biochemical measurements}

All biochemical measurements were from one of four health center laboratories located in France at Blois, Chartres, La Riche, and Orléans. The interlaboratory variability for normal and pathological values was assessed monthly. Fasting plasma glucose, measured by the glucose-oxidase method, was applied to fluorooxalated plasma using a Technicon RA100 analyzer (Bayer Diagnostics, 
Puteaux, France) or a Specific or a Delta device (Konelab, Evry, France). HbA1 $1_{c}$ was determined by high-performance liquid chromatography (L9100 ion-exchange analyzer; Hitachi/Merck-VWR, Fontenay-sous-Bois, France) or an immunoassay (DCA 2000; Bayer Diagnostics). Insulin was quantified by microparticle enzyme immunoassay with an automated analyzer (IMX; Abbott, Rungis, France). Glucose, $\mathrm{HbA} 1_{c}$ and insulin have been standardized over laboratories and over the years of the study. Indexes of insulin resistance (HOMA2-IR) [14] and beta cell secretion (HOMA2\%B) were computed using software downloaded at http://www.dtu.ox.ac.uk[15].

\section{Genotyping}

TCF7L2 single nucleotide polymorphism (SNP) rs7903146 genotyping was performed with the SNPlex TM Technology (Applied Biosystems, Foster City, CA) based on the Oligonucleotide Ligation Assay (OLA) combined with multiplex PCR target amplification (http://www.appliedbiosystems.com) [12].

\section{The RISC cohort}

RISC is a prospective observational cohort study whose rationale and methodology have been published, as well as the characteristics of the individuals recruited[11, 16]. Clinically healthy men and women, aged 30-60 years, were recruited from the local populations of 19 centres in 14 European countries. Initial exclusion criteria were: treatment for obesity, hypertension, lipid disorders or diabetes, pregnancy, cardiovascular or chronic lung disease, weight change $\geq 5 \mathrm{~kg}$ in the last 6 months, cancer (in the last 5 years) and renal failure. Exclusion criteria after screening were: arterial blood pressure $\geq 140 / 90 \mathrm{mmHg}$, fasting plasma glucose $\geq 7.0 \mathrm{mmol} / 1$, 2-hour plasma glucose (following a 75 -g OGTT) $\geq 11.0 \mathrm{mmol} / 1$, total serum cholesterol $\geq 7.8 \mathrm{mmol} / 1$, serum triacylglycerol $\geq 4.6 \mathrm{mmol} / \mathrm{l}$, and ECG abnormalities. We studied 1,047 healthy individuals (579 women and 468 men) who had an evaluation of both insulin sensitivity and insulin secretion at baseline and who 
had complete data at the three years follow up. Ethics Committee approval was obtained by each recruiting centre. Volunteers were given detailed written information on the study as well as an oral explanation, and they all signed a consent form.

Height and body weight were measured and BMI calculated.Alcohol and tobacco consumption was assessed using a standardized semi-quantitative questionnaire [17].Information on physical activity was collected with the 7-day International Physical Activity Questionnaire (IPAQ), a previously validated assessment tool for international studies, that provides a comprehensive evaluation of daily physical activity habits [18].

\section{Blood Pressure}

Blood pressure was measured in triplicateafter five minutes of rest, by trained study nurses using an OMRON 705CP (Omron Healthcare GmbH, Hamburg, Germany) with participants sitting, according to a standard protocol; the median of these readings was used in this analysis for both the baseline and the follow-up examinations. Hypertension was defined as median systolic blood pressure $\geq 140 \mathrm{mmHg}$ and/or median diastolic blood pressure $\geq 90 \mathrm{mmHg}$ or treatment for hypertension in routine care at follow-up.

\section{OGTT}

Blood samples were taken at fasting and 30, 60, 90 and 120 min into the OGTT, for central analysis of routine blood chemistry. Blood collected during the studies was separated into plasma and serum, aliquoted and stored at $-20^{\circ} \mathrm{C}$ for central assays of glucose and insulin-

Glucose concentrations were measured by the glucose oxidase technique. Plasma insulin and C-peptide were measured by a two-site time-resolved fluoroimmunoassay (AutoDELFIA Insulin kit; Wallac Oy, Turku, Finland) using monoclonal antibodies, with the following assay 
characteristics (for insulin and C-peptide, respectively): sensitivity 1-2 and 5 pmol/l, within-assay variation 5 and $5 \%$ and between-assay variation 5 and $3.5 \%$.

\section{Insulin sensitivity}

On a separate day within one month of the OGTT, participants had a hyperinsulinemic-euglycaemic clamp. Exogenous insulin was administered as a primed-continuous infusion at a rate of 240 pmol. $\mathrm{min}^{-1} \cdot \mathrm{m}^{-2}$ with a variable $20 \%$ dextrose infusion adjusted every 5-10 min to maintain plasma glucose level within $0.8 \mathrm{mmol} / \mathrm{l}( \pm 15 \%)$ of the target glucose level $(4.5-5.5 \mathrm{mmol} / \mathrm{l})$. The clamp procedure was standardised across centres[11]; the data from each clamp study were transferred to the coordinating centre, where they underwent quality control scrutiny according to pre-set criteria.

Insulin sensitivity is expressed as the ratio of the $M$ value during the final $40 \mathrm{~min}$ of the $2 \mathrm{~h}$ clamp, to the mean plasma insulin concentration measured during the same interval (M/I), normalised to fat-free mass and expressed in units of $\mu$ mol.min ${ }^{-1} \cdot \mathrm{kg}$-fat-free-mass ${ }^{-1}\left(\mathrm{nmol}^{-1}\right)^{-1}$.

\section{Insulin secretion}

Beta-cell function was assessed from the OGTT using a model describing the relationship between insulin secretion (calculated from C-peptide with the method of van Cauter et al [19] and glucose concentration, previously described in detail[20, 21]. From the model-estimated beta-cell doseresponse, relating insulin secretion (in pmol. $\min ^{-1} \cdot \mathrm{m}^{-2}$ ) to glucose concentration, insulin secretion at $5 \mathrm{mmol} / \mathrm{l}$ glucose (the average basal glucose in the subjects with normal glucose tolerance) was estimated. This parameter represents insulin secretion in basal conditions, if basal glucose were $5 \mathrm{mmol} / \mathrm{l}$ in each participant. Total insulin secretion was also determined using the model(integral during the OGTT, in nmol. $\mathrm{m}^{-2}$ )[21]. We considered, for all statistical analyses, that the product of either total insulin secretion or insulin secretion at $5 \mathrm{mmol} / \mathrm{l}$ glucose with the $\mathrm{M} / \mathrm{I}$ value from the 
clamp, to express the rate of insulin secretion, in relation with the concomitant degree of insulin resistance.

\section{Statistical analysis}

The data are expressed as mean \pm SDor as median (interquartile range) for variables with a skewed distribution, and categorical data as percentages. Variables that were not symmetrically distributed were log transformed before analyses. Baseline characteristics, means and percentages, were compared using Student's t and $\chi^{2}$ tests respectively, according to incident hypertension.

For the D.E.S.I.R. cohort, as there was no significant interaction between sex and either parental history of diabetes or the TCF7L2 genotype on the risk of hypertension, we analysed men and women together. The relations between both parental diabetes and the TCF7L2 genotype with incident hypertension were assessed by logistic regression analysis, with adjustment for gender, age and waist circumference. Further adjustments for fasting insulinemia, fasting glycemia and mean blood pressure were made. We also tested for an interaction between $\mathrm{HbA} 1_{c}>5.7 \%$ and $T C F 7 L 2$ variants on incident hypertension.

In the RISC cohort, blood pressure levels at year 3 were compared according to the quartiles of insulin secretion rate at baseline by ANOVA; we excluded individuals treated by antihypertensive medications at year 3 for this analysis.

A logistic regression analysis was used to test the association between the insulin secretion rate at baseline, assessed both as a continuous variable and stratified into quartiles, and incident hypertension at year-3 with adjustment for age, gender, recruitment centre, physical activity, waist, fasting glycaemia, systolic and diastolic blood pressure levels at baseline.

Statistical analyses used StatView (version 5.0, SAS Institute Inc.,NC) and SAS version 9.2 (SAS Institute, Cary, NC). 


\section{Results}

\section{The D.E.S.I.R. cohort}

In the D.E.S.I.R. cohort, those with incident hypertension had higher fasting glucose, $\mathrm{HbA} 1_{c}$, waist circumference, and insulin concentrations at baseline as compared to those who remained normotensive (Table 1).

Fasting glycaemia but not HbA1c levels at baseline remained associated with incident hypertension in a logistic regression analysis, after adjustment for gender and baseline age, waist circumference, and mean blood pressure. Neither HOMA2-IR nor the HOMA2\%B indices were significantly related to the risk of incident hypertension in this multivariable model.

\section{Parental history of diabetes}

A parental history of diabetes was associated with a higher incidence of hypertension at 9 years ( $36 \%$ vs $30 \%, p=0.02$ ). This association persisted after controlling for potential confounders such as waist circumference and BMI (Table 2).Further adjustment for baseline fasting glycaemia, fasting insulinaemia, HOMA2-IR andHOMA2\%B did not alter the significant relationship (Table 2).

\section{TCF7L2 genotype}

The TCF7L2 variant conformed to Hardy-Weinberg equilibrium. Blood pressure levels at baseline did not differ according to the TCF7L2 genotype. However, TCF7L2 at-risk variants $(C T+T T)$ were significantly associated with both higher systolic and diastolic blood pressure at year 9 in univariate analysis [CT+TT vs CC genotype: $137 \pm 19$ vs $135 \pm 19 \mathrm{mmHg}, p=0.02$ for systolic; 81 \pm 10 vs $80 \pm 10 \mathrm{mmHg}, p=0.01$ for diastolic blood pressure].

The presence of the T allele was associated with an increased risk of incident hypertension at year-9, after controlling for gender and age, and the association persisted after further adjustment 
for waist circumference, BMI, mean blood pressure, fasting glycaemia, insulinaemia, HOMA2-IR andHOMA2\%B at baseline (Table 3).

We further assessed whether baseline BMI or glycaemic status modified the effect of TCF7L2 at-risk allele on the risk of incident hypertension. There was no significant interaction between BMI $\left(\geq\right.$ or $\left.<27 \mathrm{~kg} / \mathrm{m}^{2}\right)$ and TCF7L2 on incident hypertension $\left(p_{\text {interaction }}=0.25\right)$. However, there was a significant interaction between baseline $\mathrm{HbA} 1_{c}$ above the median value $(\geq 5.7 \%)$ and the effect of TCF7L2 polymorphism on incident hypertension $\left(p_{\text {interaction }}=0.03\right)$. The risk of hypertension after controlling for gender, age and waist circumference was greater for individuals who carried the $\mathrm{T}$ allele with $\mathrm{HbA} 1_{\mathrm{c}} \geq 5.7 \%$ at baseline [OR: 1.82;95\% CI $(1.21,2.74), p=0.004$ ] than for those with the $\mathrm{T}$ allele but normal $\mathrm{HbA} 1_{c}<5.7 \%[1.11(0.90,1.37), p=0.3]$.

\section{The RISC cohort}

\section{Baseline glycaemia and hypertension at year 3}

In univariate analysis, both fasting and $2 \mathrm{hr}$ glycaemia at baseline were significantly associated with incident hypertension at year-3 (Table 4). However, in a multivariable analysis, the association between both fasting glycaemia [OR: $1.34 ; 95 \%$ CI $(0.96,1.86) ; p=0.09]$ and $2 \mathrm{hr}$ glycaemia [1.03; $(0.92,1.16) ; p=0.63]$ with the risk of hypertension at year-3 was no longer significant after controlling for gender, age, recruitment center and waist circumference respectively.

\section{Baseline insulin secretion and hypertension at year 3}

Individuals who developed hypertension at year-3 had at baseline, a reduced total insulin secretion during the OGTT and also a reduced basal beta-cell function at $5 \mathrm{mmol} / \mathrm{l}$ glucose, as compared to those who remained normotensive (Table 4). This suggests that individuals with subtle alterations in insulin secretion, after accounting for the concomitant degree of insulin resistance, were at higher risk of developing hypertension at follow-up. 
A lower insulin secretion rate at baseline $\left(1^{\text {st }}\right.$ vs $4^{\text {th }}$ quartile of total insulin secretion during OGTT x M/I) was associated with higher blood pressure at year 3 [SBP: $123 \pm 14$ vs $118 \pm 15$ $\mathrm{mmHg}, p=0.0001$; DBP: $78 \pm 9$ vs $74 \pm 9 \mathrm{mmHg}, p<0.0001]$. A similar inverse association was observed for basal insulin secretion at a fixed normal glucose level of $5 \mathrm{mmol} / \mathrm{l}$ from the beta-cell dose-response $\left[1^{\text {st }}\right.$ vs $4^{\text {th }}$ quartile, SBP: $125 \pm 13$ vs $116 \pm 15 \mathrm{mmHg}, p<0.0001$; DBP: $79 \pm 8$ vs 73 $\pm 9 \mathrm{mmHg}, p<0.0001]$.

The incidence of hypertension at year-3 decreased progressively across the quartiles of both total insulin secretion and insulin secretion at $5 \mathrm{mmol} / \mathrm{l}$ at baseline (Figure 1). Individuals with the lowest total insulin secretion rate during OGTT (quartile 1) had a higher incidence of hypertension as compared to those with the highest insulin secretion (quartile 4), after adjusting for other baseline risk factors (centre, age, gender, physical activity, waist circumference, smoking, alcohol intake, fasting glucose, systolic and diastolic blood pressures) [OR: 2.02; 95\% CI $(1.06,3.86), p=0.03$ ]

Similarly, the inverse association between total insulin secretion rate during the OGTT, expressed as a continuous value, and the risk of incident hypertension at 3 years remained significant in a multivariable model after controlling for centre, age, gender, physical activity, waist, smoking, alcohol intake,systolic and diastolic blood pressure levels at inclusion [OR per 1 SD log total insulin secretion: $0.75 ; 95 \% \mathrm{CI}(0.61,0.93), p=0.007]$. The addition of fasting glucose and $2 \mathrm{~h}$ glucose levels into the model did not alter the significant relationship, [OR: $0.75 ; 95 \%$ CI $(0.61$, 0.92), $p=0.007$ ] and [OR: $0.75 ; 95 \% \mathrm{CI}(0.61,0.93), p=0.007]$ respectively.

\section{Discussion}

The main finding of this study is that a genetic predisposition to type 2 diabetes and in particular the TCF7L2 at-risk allele, was significantly associated with the incidence of hypertension after a 9-year follow-up in the general population; TCF7L2 conferred an increased risk of type 2 diabetes, through alterations in insulin secretion capacity. Furthermore, we provide support for the first time, that a 
lower insulin secretion rate during an OGTT is a risk factor for the development of elevated blood pressure in a non-diabetic cohort, even after taking into account insulin resistance, as assessed by the gold standard method of the clamp.

Previous evidence has shown that offspring of patients with type 2 diabetes have an increased risk of developing type 2 diabetes, with defects in early beta-cell secretion[22-25]. It has also been suggested that these offspring have early autonomic dysfunction, even in the absence of glucose intolerance[26], and more often display metabolic abnormalitieswith high insulin levels and arterial hypertension[27, 28].In a previous community-based cohort, parental diabetes appeared as an independent predictor of longitudinal changes in both systolic and diastolic blood pressures in the offspring, regardless of race and gender[29]. Taken together, these observations and our results suggest that heritable factors related with type 2 diabetes, increase the risk of various disorders, including hypertension.

Genetic susceptibility totype 2 diabetesseems to be more related to early beta-cell dysfunction rather than to insulin resistance $[30,31]$. We selected the TCF7L2 polymorphism as this variant that has the largest effect on type 2 diabetessusceptibility among the predisposing genes discovered to date[10, 32]. To our knowledge, this is the first report to study the longitudinal relation of theTCF7L2 genotypeon incident hypertension in the general population. It has been demonstrated that the at-risk TCF7L2 genotype is associated with impaired insulin secretion[33] and a reduced sensitivity of the beta-cell to incretins[34].The fact that the effect of the TCF7L2 polymorphism on blood pressure was independent of waist circumference, glycaemia or the insulinresistance HOMA2-IR index, underscores the potential role of insulin secretion defects on the evolution of blood pressure over time. This is highlighted by our data on the relationship between both total and basal insulin secretion and 3-year incident hypertension in the RISC cohort. However, we suggest that the association of the TCF7L2 genotype with incident hypertension might be related, at least in part, to reduced GLP-1 secretion in these individuals, as recent evidence 
suggested that incretins may modulate blood pressure [35]. The TCF7L2 variant may then affect primarily the incretin levels, and as a consequence, have independent effects on blood pressure and on insulin secretion.

Our longitudinal results are in favor of a positive interaction between subtle elevations in glycaemia and genetic predisposition leading to defects in insulin secretion in the development of hypertension. Our results are consistent with recent genetic data showing an association between the TCF7L2 variant and increased systolic blood pressure in an endogamous ethnic group from India [36].However, it should be noted that a recent large GWAS study did not report a significant association between the TCF7L2 variant rs7903146 and blood pressure, although a trend was observed for systolic blood pressure $(\mathrm{p}=0.06)$ and pulse pressure $(\mathrm{p}=0.04)$ [37].A regional plot around TCF7L2locus from the data publicly available of the ICBP GWAS study suggest that a signal near rs7903146may modulate BP, although this variant doesn't appear to be a glycaemic signal (data not shown). The differences between our present study and the GWAS report may be related to the longitudinal follow-up used in our study as opposed to the case-control design used in the GWAS study. Indeed, we did not observe a significant association between the TCF7L2 variant and the presence of hypertension in a cross-sectional analysis of the entire D.E.S.I.R. cohort at baseline (data not shown). Furthermore, in our study, we found that a large part of the association of the TCF7L2 variant with hypertension was observed in people who already had $\mathrm{HbA} 1_{\mathrm{c}}$ at baseline above the median value ( $\geq 5.7 \%$ ), which may explain why TCF7L2 locus did not appear as being associated with hypertension in large GWAS cross-sectional studies that were not stratified on glucose. Our results need to be confirmed in other large prospective cohorts with a long follow-up. The causal role of insulin in the development of hypertension has been much debated. It has been proposed that insulin resistance and/or hyperinsulinaemia promote the development of elevated blood pressure over time $[5,6,38,39]$ with a positive association between insulin levels and incident hypertension $[39,40]$. In these studies, the insulin secretion rate was not specifically 
assessed. Our findings confirm an association between fasting insulinaemia and blood pressure but however suggest a greater role for reduced insulin secretion in the pathogenesis of hypertension. Fasting insulin is a marker of insulin resistance which could be confounded by the presence of subtle defects in insulin secretion.

To our knowledge, the effects of insulin secretion on blood pressure evolution have not been investigated previously, in contrast to the role of insulin resistance.In the present study, we found that a lower total insulin secretion rate was significantly associated with the incidence of hypertension in non-diabetic people, and that this effect was independent of insulin sensitivity. This observation was confirmed when we assessed basal insulin secretion at a fixed normal glucose level of $5 \mathrm{mmol} / \mathrm{l}$ glucose, from the beta-cell dose-response. Interestingly, in the present study, the inverse association between insulin secretion and incident hypertension was not related to weight gain over the follow-up (data not shown) and was also independent of insulin resistance, as assessed by the gold-standard method of the clamp, suggesting alternative mechanisms.

Potential mechanisms that may explain the increase in hypertension risk with a reduced insulin secretion rate, may be the protective action exerted by insulin on the blood vessel. Hemodynamic actions of insulin have been suggested [41] and a small blood-pressure lowering effect of insulin has been described in non-diabetic individuals [42]. Furthermore, a partial or complete deficiency in the insulin receptor and/or the insulin-receptor substrate-1 in the endothelial cells, is associated in mice, with endothelial dysfunction and increased blood pressure $[43,44]$. Together these findings suggest that a reduced activation of the insulin pathway through diminished insulin secretion capacity, particularly in the presence of insulin resistance, may lead to endothelial dysfunction that favors the development of hypertension. Hyperinsulinaemia has to be interpreted as a compensation for enhanced insulin resistance. If this compensation is insufficient, the net effect at the cellularlevel, including probably the endothelium, is a down-tuned insulin signal. 
Furthermore, recent evidence suggests that improving insulin secretion via the modulation of incretin concentrations may lower blood pressure, even in non-diabetic hypertensive individuals $[45,46]$.

In parallel, subtle defects in beta cell function may facilitate development of hypertension through possible repeated post-prandial elevations in glucose levels over time. Glycemic variability may contribute to increase blood pressure through chronic induction of inflammation and enhanced oxidative stress $[47,48]$. Oxidative stress has been shown to correlate with both glycemic fluctuations and blood pressure variability, suggesting possible alternative mechanisms to explain the increased incidence of hypertension in relation to subtle defects in beta cell function [49]. In addition, the STOP-NIDDMtrial has shown that acarbose treatment, which reduces postprandial hyperglycemia, was associated with a significant reduction in the development of incident hypertensionin those with impaired glucose tolerance, suggesting an impact of postprandial excursions on blood pressure [50].This point needs to be specifically investigated in another prospective study with ambulatory, continuous assessment of glucose values.

Limitations of the present study include the absence of accurate measures of both insulin resistanceand beta cell function over time in the D.E.S.I.R. cohort, which precludes us from demonstrating that the association between parental history, the TCF7L2genotype and incident hypertension is directly related to defects in beta cell function. It is possible that the association observed between parental history and hypertension may be related, at least in part, to enhanced insulin resistance in the parents. The number of individuals with the at-risk TCF7L2genotype was limited, in comparison with large genetic consortium studies and our results, albeit being significant, need to be replicated in other populations. Furthermore, the absence of postprandial glucose levels did not allow us to investigate the exact role of this genotype on the development of elevated blood pressure. The strengths of the present study are the use of two complimentary 
cohorts specifically dedicated to the study of glucose metabolism, with a large number of normotensive participants at inclusion, aligned laboratory assays, continuous quality control of data. The RISC cohort is the largest cohort available with both a systematic evaluation of insulin secretion and gold standard measures of insulin sensitivity by the glucose clamp technique, which provided the opportunity to clarify the role of alterations of insulin secretion in hypertension. For this important question to be addressed, a large number of individuals with high quality measures of glucose metabolism is required.

In conclusion, our study shows that a parental history of type 2 diabetes and at-risk variants in the TCF7L2genotype predispose to incident hypertension. The novel finding of the association between reduced insulin secretion and the development of elevated blood pressure deserves further investigations with the study of the impact of treatments targeting insulin secretion and postprandial hyperglycemia on blood pressure. Our results suggest that defects in insulin secretion may be a new independent risk factor for the development of hypertension.

\section{The list of the D.E.S.I.R. Study Group and RISC investigators is presented in the ESM.}

\section{Author contributions}

FB was responsible for the conception of the study, analysed data, and wrote the manuscript; RR, $\mathrm{BB}, \mathrm{EF}$ and $\mathrm{AN}$ reviewed the manuscript andcontributed to the discussion, CL, SC and LY analysed the data, ML, JP, PF, OL and MM reviewed the manuscript. All authors approved the final version.

\section{Acknowledgements and funding}

The D.E.S.I.R. study has been supported by INSERM contracts with CNAMTS, Lilly, Novartis Pharma and Sanofi-Aventis; by INSERM (Réseaux en Santé Publique, Interactions entre les déterminants de la santé), Cohortes Santé TGIR, the Association Diabète Risque Vasculaire, the Fédération Française de Cardiologie, La Fondation de France,ALFEDIAM, ONIVINS, Ardix 
Medical, Bayer Diagnostics, Becton Dickinson, Cardionics, Merck Santé, Novo Nordisk, Pierre Fabre, Roche, Topcon.

The RISC Study was supported by EU grantQLG1-CT-2001-01252, with additional support from AstraZeneca(Sweden). The EGIR group activities are supported by an unrestrictedresearch grant from Merck Serono, France. For details of the RISCstudy and investigators

Duality of interest The authors declare that there is no duality ofinterest associated with this manuscript.

\section{References}

1 Ferrannini E, Cushman WC (2012) Diabetes and hypertension: the bad companions. Lancet 380: 601-610

2 Conen D, Ridker PM, Mora S, Buring JE, Glynn RJ (2007) Blood pressure and risk of developing type 2 diabetes mellitus: the Women's Health Study. European heart journal 28: 29372943

3 Gress TW, Nieto FJ, Shahar E, Wofford MR, Brancati FL (2000) Hypertension and antihypertensive therapy as risk factors for type 2 diabetes mellitus. Atherosclerosis Risk in Communities Study. The New England journal of medicine 342: 905-912

4 Bjornholt JV, Erikssen G, Kjeldsen SE, Bodegard J, Thaulow E, Erikssen J (2003) Fasting blood glucose is independently associated with resting and exercise blood pressures and development of elevated blood pressure. J Hypertens 21: 1383-1389

$5 \quad$ He J, Klag MJ, Caballero B, Appel LJ, Charleston J, Whelton PK (1999) Plasma insulin levels and incidence of hypertension in African Americans and whites. Archives of internal medicine 159: 498-503

6 Fagot-Campagna A, Balkau B, Simon D, Ducimetiere P, Eschwege E (1997) Is insulin an independent risk factor for hypertension? The Paris Prospective Study. International journal of epidemiology 26: 542-550

7 Bower JK, Appel LJ, Matsushita K et al. (2012) Glycated hemoglobin and risk of hypertension in the atherosclerosis risk in communities study. Diabetes Care 35: 1031-1037

8 Britton KA, Pradhan AD, Gaziano JM et al. (2011) Hemoglobin A1c, body mass index, and the risk of hypertension in women. Am J Hypertens 24: 328-334

9 Gloyn AL, Braun M, Rorsman P (2009) Type 2 diabetes susceptibility gene TCF7L2 and its role in beta-cell function. Diabetes 58: 800-802

10 Florez JC, Jablonski KA, Bayley N et al. (2006) TCF7L2 polymorphisms and progression to diabetes in the Diabetes Prevention Program. The New England journal of medicine 355: 241-250

11 Hills SA, Balkau B, Coppack SW et al. (2004) The EGIR-RISC STUDY (The European group for the study of insulin resistance: relationship between insulin sensitivity and cardiovascular disease risk): I. Methodology and objectives. Diabetologia 47: 566-570

12 Gautier A, Roussel R, Lange C et al. (2011) Effects of genetic susceptibility for type 2 diabetes on the evolution of glucose homeostasis traits before and after diabetes diagnosis: data from the d.e.s.I.R. Study. Diabetes 60: 2654-2663 
13 Bonnet F, Marre M, Halimi JM et al. (2006) Waist circumference and the metabolic syndrome predict the development of elevated albuminuria in non-diabetic subjects: the DESIR Study. J Hypertens 24: 1157-1163

14 Matthews DR, Hosker JP, Rudenski AS, Naylor BA, Treacher DF, Turner RC (1985) Homeostasis model assessment: insulin resistance and beta-cell function from fasting plasma glucose and insulin concentrations in man. Diabetologia 28: 412-419

15 Antuna-Puente B, Disse E, Rabasa-Lhoret R, Laville M, Capeau J, Bastard JP (2011) How can we measure insulin sensitivity/resistance? Diabetes Metab 37: 179-188

16 Bonnet F, Patel S, Laville M et al. (2008) Influence of the ACE gene insertion/deletion polymorphism on insulin sensitivity and impaired glucose tolerance in healthy subjects. Diabetes Care 31: 789-794

17 Bonnet F, Disse E, Laville M et al. (2012) Moderate alcohol consumption is associated with improved insulin sensitivity, reduced basal insulin secretion rate and lower fasting glucagon concentration in healthy women. Diabetologia 55: 3228-3237

18 Craig CL, Marshall AL, Sjostrom M et al. (2003) International physical activity questionnaire: 12-country reliability and validity. Med Sci Sports Exerc 35: 1381-1395

19 Van Cauter E, Mestrez F, Sturis J, Polonsky KS (1992) Estimation of insulin secretion rates from C-peptide levels. Comparison of individual and standard kinetic parameters for C-peptide clearance. Diabetes 41: 368-377

20 Mari A, Schmitz O, Gastaldelli A, Oestergaard T, Nyholm B, Ferrannini E (2002) Meal and oral glucose tests for assessment of beta -cell function: modeling analysis in normal subjects. American journal of physiology Endocrinology and metabolism 283: E1159-1166

21 Mari A, Tura A, Natali A et al. (2010) Impaired beta cell glucose sensitivity rather than inadequate compensation for insulin resistance is the dominant defect in glucose intolerance. Diabetologia 53: 749-756

22 O'Rahilly S, Turner RC, Matthews DR (1988) Impaired pulsatile secretion of insulin in relatives of patients with non-insulin-dependent diabetes. The New England journal of medicine 318: $1225-1230$

23 Meigs JB, Cupples LA, Wilson PW (2000) Parental transmission of type 2 diabetes: the Framingham Offspring Study. Diabetes 49: 2201-2207

24 Bonadonna RC, Stumvoll M, Fritsche A et al. (2003) Altered homeostatic adaptation of first- and second-phase beta-cell secretion in the offspring of patients with type 2 diabetes: studies with a minimal model to assess beta-cell function. Diabetes 52: 470-480

25 Vauhkonen I, Niskanen L, Vanninen E, Kainulainen S, Uusitupa M, Laakso M (1998) Defects in insulin secretion and insulin action in non-insulin-dependent diabetes mellitus are inherited. Metabolic studies on offspring of diabetic probands. J Clin Invest 101: 86-96

26 Frontoni S, Bracaglia D, Baroni A et al. (2003) Early autonomic dysfunction in glucosetolerant but insulin-resistant offspring of type 2 diabetic patients. Hypertension 41: 1223-1227 27 Haffner SM, Stern MP, Hazuda HP, Mitchell BD, Patterson JK, Ferrannini E (1989) Parental history of diabetes is associated with increased cardiovascular risk factors. Arteriosclerosis 9: 928-933

28 Pontiroli AE, Monti LD, Pizzini A, Piatti P (2000) Familial clustering of arterial blood pressure, HDL cholesterol, and pro-insulin but not of insulin resistance and microalbuminuria in siblings of patients with type 2 diabetes. Diabetes care 23: 1359-1364

29 Srinivasan SR, Frontini MG, Berenson GS (2003) Longitudinal changes in risk variables of insulin resistance syndrome from childhood to young adulthood in offspring of parents with type 2 diabetes: the Bogalusa Heart Study. Metabolism: clinical and experimental 52: 443-450; discussion 451-443

$30 \quad$ Florez JC (2008) Newly identified loci highlight beta cell dysfunction as a key cause of type 2 diabetes: where are the insulin resistance genes? Diabetologia 51: 1100-1110 
31 Drong AW, Lindgren CM, McCarthy MI (2012) The genetic and epigenetic basis of type 2 diabetes and obesity. Clinical pharmacology and therapeutics 92: 707-715

32 Cauchi S, Meyre D, Choquet H et al. (2006) TCF7L2 variation predicts hyperglycemia incidence in a French general population: the data from an epidemiological study on the Insulin Resistance Syndrome (DESIR) study. Diabetes 55: 3189-3192

33 Lyssenko V, Lupi R, Marchetti P et al. (2007) Mechanisms by which common variants in the TCF7L2 gene increase risk of type 2 diabetes. J Clin Invest 117: 2155-2163

34 Villareal DT, Robertson H, Bell GI et al. (2010) TCF7L2 variant rs7903146 affects the risk of type 2 diabetes by modulating incretin action. Diabetes 59: 479-485

35 Yerram P, Whaley-Connell A (2012) Novel role for the incretins in blood pressure regulation. Current opinion in nephrology and hypertension 21: 463-468

36 Gupta V, Khadgawat R, Ng HK et al. (2012) Association of TCF7L2 and ADIPOQ with body mass index, waist-hip ratio, and systolic blood pressure in an endogamous ethnic group of India. Genetic testing and molecular biomarkers 16: 948-951

37 Ehret GB, Munroe PB, Rice KM et al. (2011) Genetic variants in novel pathways influence blood pressure and cardiovascular disease risk. Nature 478: 103-109

38 Arnlov J, Pencina MJ, Nam BH et al. (2005) Relations of insulin sensitivity to longitudinal blood pressure tracking: variations with baseline age, body mass index, and blood pressure. Circulation 112: 1719-1727

39 Liese AD, Mayer-Davis EJ, Chambless LE et al. (1999) Elevated fasting insulin predicts incident hypertension: the ARIC study. Atherosclerosis Risk in Communities Study Investigators. J Hypertens 17: 1169-1177

40 Xun P, Liu K, Cao W, Sidney S, Williams OD, He K (2012) Fasting insulin level is positively associated with incidence of hypertension among American young adults: a 20-year follow-up study. Diabetes Care 35: 1532-1537

41 Baron AD (1994) Hemodynamic actions of insulin. Am J Physiol 267: E187-202

42 Heise T, Magnusson K, Heinemann L, Sawicki PT (1998) Insulin resistance and the effect of insulin on blood pressure in essential hypertension. Hypertension 32: 243-248

43 Rask-Madsen C, Li Q, Freund B et al. (2010) Loss of insulin signaling in vascular endothelial cells accelerates atherosclerosis in apolipoprotein E null mice. Cell metabolism 11: 379389

44 Galkina EV, Butcher M, Keller SR et al. (2012) Accelerated atherosclerosis in Apoe-/- mice heterozygous for the insulin receptor and the insulin receptor substrate-1. Arteriosclerosis, thrombosis, and vascular biology 32: 247-256

45 Mistry GC, Maes AL, Lasseter KC et al. (2008) Effect of sitagliptin, a dipeptidyl peptidase4 inhibitor, on blood pressure in nondiabetic patients with mild to moderate hypertension. Journal of clinical pharmacology 48: 592-598

46 Koren S, Shemesh-Bar L, Tirosh A et al. (2012) The effect of sitagliptin versus glibenclamide on arterial stiffness, blood pressure, lipids, and inflammation in type 2 diabetes mellitus patients. Diabetes technology \& therapeutics 14: 561-567

47 Cherney DZ, Scholey JW, Sochett E, Bradley TJ, Reich HN (2011) The acute effect of clamped hyperglycemia on the urinary excretion of inflammatory cytokines/chemokines in uncomplicated type 1 diabetes: a pilot study. Diabetes Care 34: 177-180

48 Monnier L, Mas E, Ginet C et al. (2006) Activation of oxidative stress by acute glucose fluctuations compared with sustained chronic hyperglycemia in patients with type 2 diabetes. JAMA : the journal of the American Medical Association 295: 1681-1687

49 Di Flaviani A, Picconi F, Di Stefano P et al. (2011) Impact of glycemic and blood pressure variability on surrogate measures of cardiovascular outcomes in type 2 diabetic patients. Diabetes Care 34: 1605-1609 
50 Chiasson JL, Josse RG, Gomis R, Hanefeld M, Karasik A, Laakso M (2003) Acarbose treatment and the risk of cardiovascular disease and hypertension in patients with impaired glucose tolerance: the STOP-NIDDM trial. JAMA : the journal of the American Medical Association 290: 486-494 
Table 1. Baseline characteristics of participants in the D.E.S.I.R. cohort according to incident hypertension (HTA) over the 9-year follow-up.

\begin{tabular}{lccc} 
& $\begin{array}{c}\text { Without incident } \\
\text { HTA } \\
\text { n=1646 }\end{array}$ & $\begin{array}{c}\text { With incident } \\
\text { HTA } \\
\text { n=745 }\end{array}$ & $P$ \\
\hline Age (years) & $44 \pm 9$ & $49(9)$ & 0.0001 \\
Men (\%) & $41 \%$ & $52 \%$ & 0.0001 \\
BMI (kg/m ${ }^{2}$ ) & $23.4 \pm 3.0$ & $24.8 \pm 3.3$ & 0.0001 \\
Waist circumference (cm) & $78 \pm 10$ & $84 \pm 10$ & 0.0001 \\
Smoking & $21 \%$ & $20 \%$ & 0.4 \\
Systolic blood pressure (mmHg) & $121 \pm 9$ & $127 \pm 7$ & 0.0001 \\
Diastolic blood pressure (mmHg) & $75 \pm 7$ & $78 \pm 6$ & 0.0001 \\
Fasting glucose (mmol/l) & $5.17 \pm 0.55$ & $5.41 \pm 0.88$ & 0.0001 \\
HbA1 $(\%)$ & $5.35 \pm 0.40$ & $5.50 \pm 0.55$ & 0.0001 \\
HbA1c (mmol/mol) & $33.2 \pm 2.48$ & $34.1 \pm 3.41$ & 0.0001 \\
Fasting insulin (pmol/l) $*$ & $39.9(20.8)$ & $45.3(23.3)$ & 0.0001 \\
HOMA2-IR* & $1.55(0.91)$ & $1.29(0.73)$ & 0.0001 \\
HOMA2\%B* & $83.6(25.7)$ & $82.5(25.2)$ & 0.3 \\
\hline
\end{tabular}

Data shown are as mean (standard deviation), median (interquartile range) or $\%$

* $\log$ transformation for statistical analysis 
Table 2. Association between parental history of diabetes and incident hypertension in the D.E.S.I.R. cohort

\begin{tabular}{lcc} 
& OR (95\% CI) & $P$ \\
\hline Unadjusted & $1.30(1.04-1.64)$ & 0.02 \\
Adjusted for gender, age & $1.45(1.14-1.84)$ & 0.003 \\
Adjusted for gender, & $1.41(1.10-1.80)$ & 0.006 \\
Adjusted for gender, age, waist & $1.41(1.11-1.81)$ & 0.006 \\
Adjusted for gender, age, waist, HbA1c & $1.40(1.09-1.79)$ & 0.008 \\
Adjusted for gender, age, waist, fasting glucose, fasting insulin & $1.37(1.07-1.76)$ & 0.01 \\
Adjusted for gender, age, waist, mean BP, smoking, HOMA-IR & $1.37(1.06-1.77)$ & 0.02 \\
Adjusted for gender, age, waist, fasting glucose, mean BP, & & \\
smoking, alcohol intake & $1.39(1.04-1.86)$ & 0.03 \\
Adjusted for gender, age, waist, mean BP, smoking, alcohol & $1.39(1.04-1.87)$ & 0.03 \\
intake, HOMA-IR & & \\
\hline
\end{tabular}


Table 3. Association between TCF7L2at-risk variants and incident hypertension (CT+TT vs CC as reference) in the D.E.S.I.R. cohort

\begin{tabular}{lcc} 
& OR (95\% CI) & $P$ \\
\hline Unadjusted & $1.15(0.96-1.36)$ & 0.12 \\
Adjusted for gender, age & $1.23(1.02-1.47)$ & 0.03 \\
Adjusted for gender, age, BMI & $1.22(1.02-1.47)$ & 0.03 \\
Adjusted for gender, age, waist & $1.22(1.01-1.47)$ & 0.03 \\
Adjusted for gender, age, waist, HbA1c & $1.22(1.02-1.47)$ & 0.03 \\
Adjusted for gender, age, waist, fasting glucose, fasting insulin & $1.22(1.01-1.47)$ & 0.03 \\
Adjusted for gender, age, waist, mean BP, smoking, HOMA-IR & $1.31(1.08-1.59)$ & 0.006 \\
Adjusted for gender, age, waist, fasting glucose, mean BP, & & \\
smoking, alcohol intake & $1.38(1.11-1.73)$ & 0.004 \\
Adjusted for gender, age, waist, mean BP, smoking, alcohol & $1.40(1.12-1.75)$ & 0.003 \\
intake, HOMA-IR & & \\
\hline
\end{tabular}


Table 4. Baseline characteristics in the RISC cohort according to incident hypertension (HTA) over the 3-year follow-up

\begin{tabular}{lccc}
\hline & $\begin{array}{c}\text { Without incident } \\
\text { HTA } \\
(\mathrm{n}=881)\end{array}$ & $\begin{array}{c}\text { With incident } \\
\text { HTA } \\
(\mathrm{n}=166)\end{array}$ & $P$ \\
\hline Age (years) & $43.9 \pm 8.2$ & $47.7 \pm 8.1$ & $<0.0001$ \\
Waist (cm) & $86 \pm 12$ & $92 \pm 12$ & $<0.0001$ \\
BMI (kg/m²) & $25.1 \pm 3.7$ & $27.2 \pm 4.3$ & $<0.0001$ \\
Smoker (\%) & 26.3 & 26.7 & 0.92 \\
Physically inactive (\%) & 19.3 & 22.0 & 0.43 \\
Systolic blood pressure (mmHg) & $116 \pm 12$ & $128 \pm 10$ & $<0.0001$ \\
Diastolic blood pressure (mmHg) & $74 \pm 8$ & $80 \pm 7$ & $<0.0001$ \\
Fasting glucose (mmol/L) & $5.1 \pm 0.5$ & $5.3 \pm 0.6$ & $<0.0001$ \\
2hr glucose (mmol/l) & $6.1 \pm 1.7$ & $5.7 \pm 1.5$ & 0.02 \\
Fasting insulin (pmol/l)* & $29.5(21.0)$ & $36.0(25.7)$ & $<0.0001$ \\
Clamp Insulin Sensitivity (M/I) * & $134(88)$ & $114(76)$ & $<0.0001$ \\
Total insulin secretion† x M/I* & $50.8(29.7)$ & $46.2(25.8)$ & 0.0005 \\
Insulin secretion at 5 mmol† x M/I* & $90.0(72.7)$ & $74.2(71.5)$ & 0.002 \\
\hline Data shown are as mean \pm standard & & & \\
\hline
\end{tabular}

Data shown are as mean \pm standard deviation, median (interquartile range) or $n$

*log-transformed for analysis

†Total insulin secretion during the OGTT at baseline, and insulin secretion at $5 \mathrm{mmol} / \mathrm{l}$ are both expressed in relation to the M/I value $\left(\mathrm{nmol} \mathrm{m} \mathrm{mmol} \mathrm{min}^{-1} \mathrm{kgffm}^{-1} \mathrm{nmol}^{-1}\right.$ ) and multiplied by $10^{-2}$ for simplification of presentation 
Fig 1

A

Incidence of hypertension (\%)

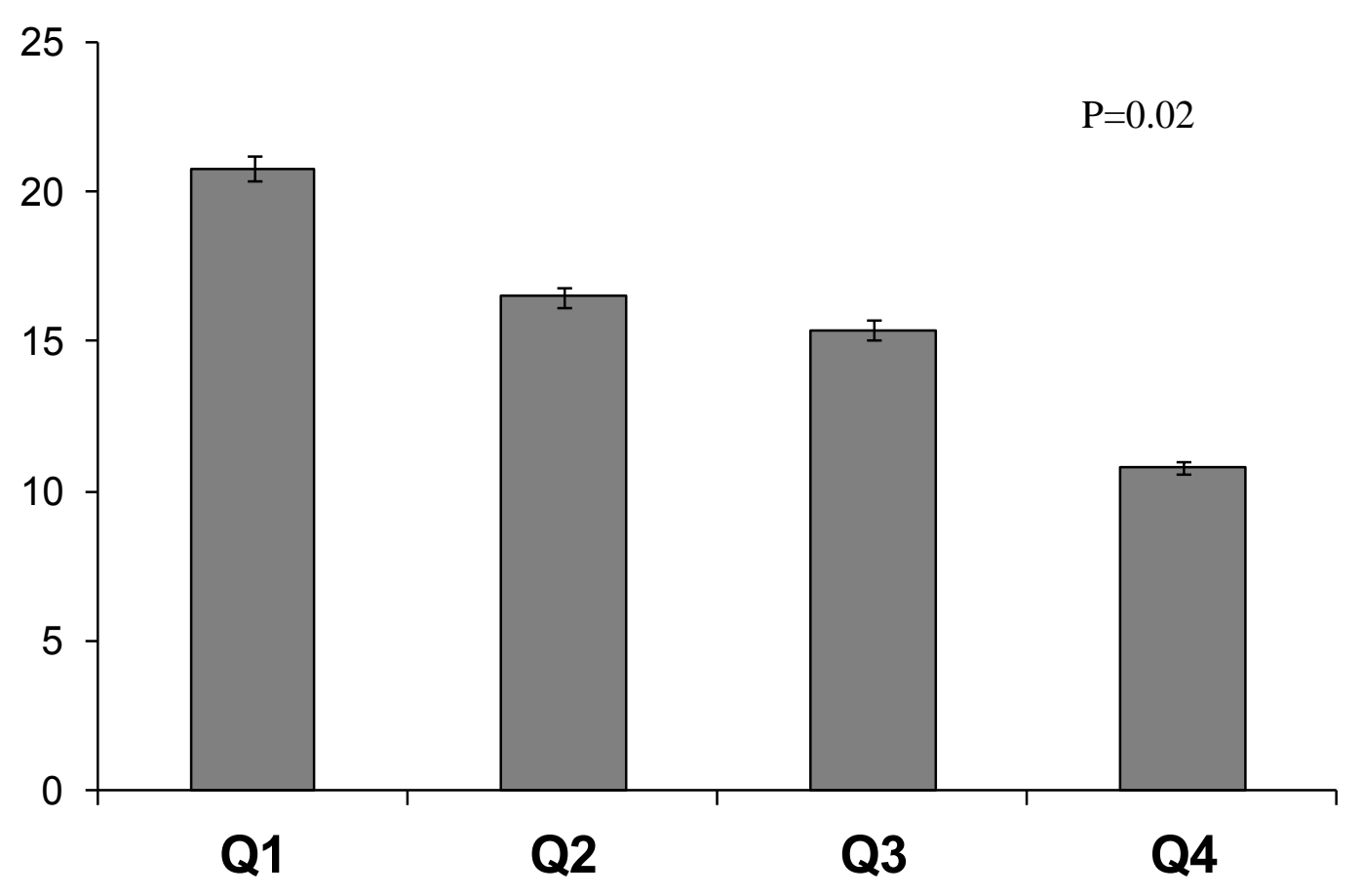

B

Incidence of hypertension (\%)

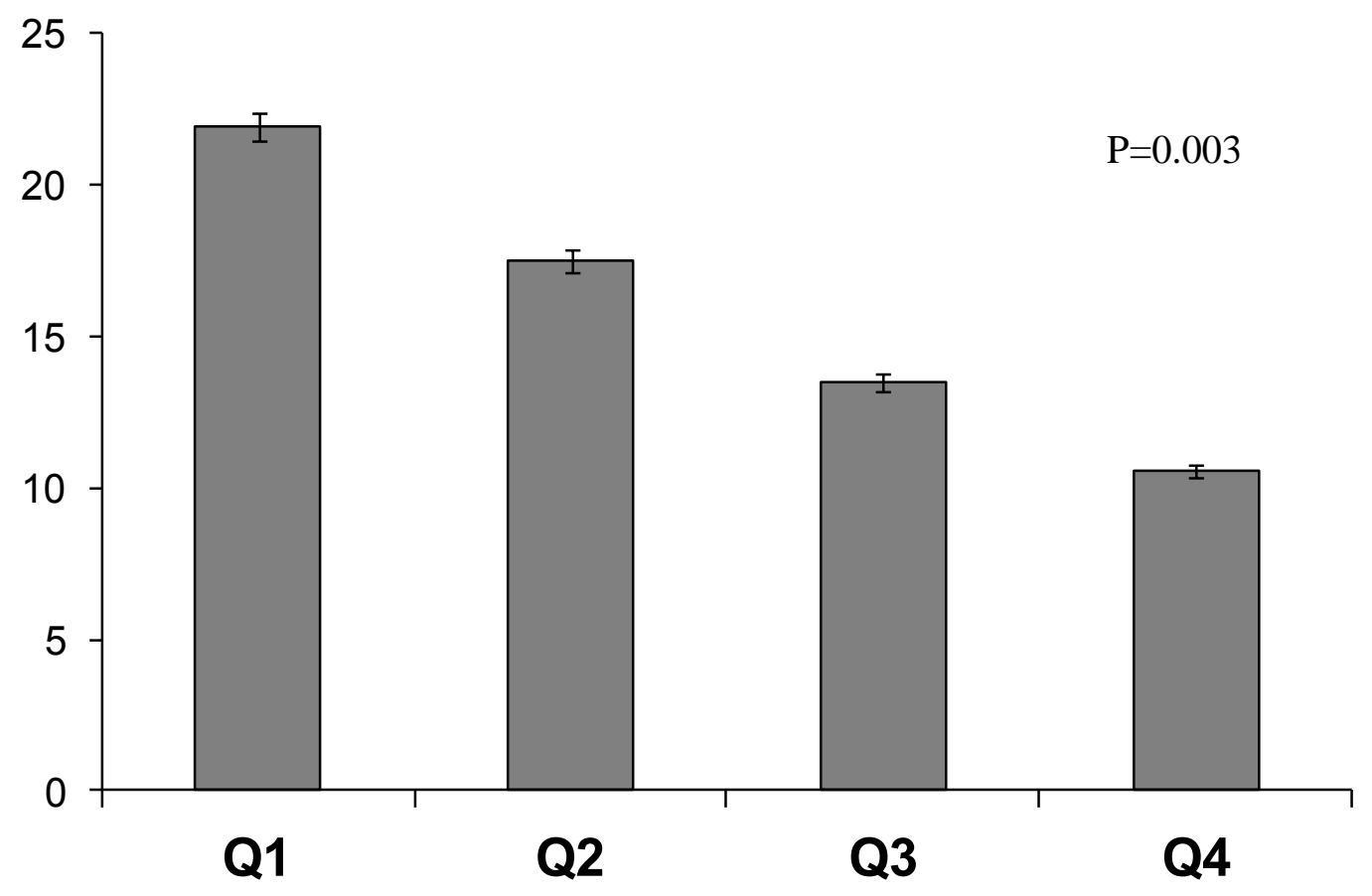




\section{Legends for figure}

Fig.1Incidence of hypertension at year-3 according to the quartiles of (A) total insulin secretion rate $\mathrm{x}$ M/I during the OGTT (B) basal insulin secretion rate at $5 \mathrm{mmol}$ glucose $\mathrm{x} \mathrm{M} / \mathrm{I}$ at inclusion in the RISC cohort. The $p$ value is for trend. 
